\title{
Population-based meta-analysis of chloroquine: informing chloroquine pharmacokinetics in COVID-19 patients
}

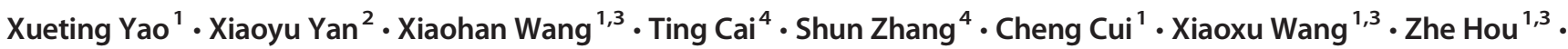 \\ Qi Liu ${ }^{1,5} \cdot$ Haiyan $\mathrm{Li}^{1,6} \cdot$ Jing $\mathrm{Lin}^{4} \cdot \mathrm{Zi}^{\mathrm{X}}$ Xiong ${ }^{4} \cdot$ Dongyang Liu ${ }^{1}$ (B)
}

Received: 28 May 2020 / Accepted: 25 October 2020 / Published online: 13 November 2020

(C) The Author(s) 2020

\begin{abstract}
Aims Chloroquine (CQ) has been repurposed to treat coronavirus disease 2019 (COVID-19). Understanding the pharmacokinetics (PK) in COVID-19 patients is essential to study its exposure-efficacy/safety relationship and provide a basis for a possible dosing regimen optimization.

Subject and methods In this study, we used a population-based meta-analysis approach to develop a population PK model to characterize the CQ PK in COVID-19 patients. An open-label, single-center study (ethical review approval number: PJ-NBEYKY-2020-063-01) was conducted to assess the safety, efficacy, and pharmacokinetics of CQ in patients with COVID-19. The sparse PK data from 50 COVID-19 patients, receiving $500 \mathrm{mg}$ CQ phosphate twice daily for 7 days, were combined with additional CQ PK data from 18 publications.

Results A two-compartment model with first-order oral absorption and first-order elimination and an absorption lag best described the data. Absorption rate (ka) was estimated to be $0.559 \mathrm{~h}^{-1}$, and a lag time of absorption (ALAG) was estimated to be 0.149 h. Apparent clearance (CL/F) and apparent central volume of distribution (V2/F) was $33.3 \mathrm{l} / \mathrm{h}$ and 36301 . Apparent distribution clearance $(\mathrm{Q} / \mathrm{F})$ and volume of distribution of peripheral compartment (Q3/F) were $58.7 \mathrm{l} / \mathrm{h}$ and 51201 . The simulated CQ concentration under five dosing regimens of CQ phosphate were within the safety margin $(400 \mathrm{ng} / \mathrm{ml})$.

Conclusion Model-based simulation using PK parameters from the COVID-19 patients shows that the concentrations under the currently recommended dosing regimen are below the safety margin for side-effects, which suggests that these dosing regimens are generally safe. The derived population PK model should allow for the assessment of pharmacokinetics-pharmacodynamics (PK-PD) relationships for CQ when given alone or in combination with other agents to treat COVID-19.
\end{abstract}

Keywords Chloroquine $\cdot$ Population pharmacokinetics $\cdot$ Coronavirus disease 2019

\section{Introduction}

The outbreak of coronavirus disease 2019 (COVID-19) has quickly become a global pandemic since December 2019.

Xueting Yao, Xiaoyu Yan, Xiaohan Wang, Ting Cai and Shun Zhang contributed equally to this work.

Dongyang Liu

liudongyang@vip.sina.com

1 Drug Clinical Trial Center, Peking University Third Hospital, Beijing 100191, China

2 School of Pharmacy, Faculty of Medicine, The Chinese University of Hong Kong, Shatin, New Territories, Hong Kong Special Administrative Region 999077, China

3 School of Basic Medicine and Clinical Pharmacy, China Pharmaceutical University, Nanjing 211198, China
Although no treatment has demonstrated clinical efficacy against COVID-19, various drugs are being repositioned to treat COVID-19 and are being tested clinically. Chloroquine (CQ) phosphate has been shown to effectively suppress

4 Key Laboratory of Diagnosis and Treatment of Digestive System Tumors of Zhejiang Province, HwaMei Hospital, University of Chinese Academy of Sciences (Ningbo No.2 Hospital), Ningbo 315010, China

5 Department of Orthopedics, Peking University Third Hospital, Beijing 100191, China

6 Department of Cardiology and Institute of Vascular Medicine, Peking University Third Hospital, Beijing 100191, China 
SARS-CoV-2 in vitro assay $[1,2]$. Preliminary data from clinical trials also demonstrate its beneficial effect such as reducing the deterioration of pneumonia, improving the lungimaging results, decreasing the viral load, and shortening the disease duration [3]. This drug is recommended in the guidelines for the prevention, diagnosis, and treatment of pneumonia caused by COVID-19, issued by the National Health Commission of the People's Republic of China [4]. The US Food and Drug Administration has also issued an emergency use authorization (EUA) to permit the emergency use of chloroquine phosphate in patients with COVID-19 under certain conditions [5].

Chloroquine has been shown to be widely distributed in tissues and organs, where apparent distribution volume was up to $13,000-65,0001$ (about $2001 / \mathrm{kg}$ in whole blood and $8001 / \mathrm{kg}$ in plasma) [6]. About $30 \%-50 \%$ of the CQ was metabolized in the liver by CYP2C8, CYP3A4, and CYP2D6, where CYP2C8 contributed about $60 \%$ and CYP3A4 contributed $25 \%$ of metabolism [7]. The accumulation of CQ in organs and blood cells resulted in its relatively slow clearance, and a long half-life of 20-60 days [6]. So far, no PK data of CQ in COVID-19 patients has been reported.

Chloroquine phosphate has been used for the treatment of malaria and autoimmune diseases for over 70 years. It is also used for prophylaxis of malaria for people returning from malaria-endemic geographic areas [8]. According to the prescribing information, the dosage on the first day is not to exceed $1500 \mathrm{mg}$, followed by a daily maintenance dose not to exceed $1000 \mathrm{mg}$. The major safety concern involves QT prolongation, ventricular tachycardia, and retinopathy [9]. The cardiotoxicity after CQ administration included hypotension, QT interval prolongation, cardiomyopathy, arrhythmia, and ventricular tachycardia. After receiving $600 \mathrm{mg} \mathrm{CQ}$, adult volunteers had a mean $16 \mathrm{~ms}$ (95\% confidence interval 9-23) prolongation of the Bazett corrected QT interval [10]. The mean CQ $\mathrm{IC}_{50}$ value for hERG channel inhibition in Xenopus oocytes has been mesasured at $8.4 \mu \mathrm{mol} / \mathrm{l}(2700 \mathrm{ng} / \mathrm{ml})$ [11], which suggested that only very high concentrations in vivo might cause clinically significant QT prolongation.

The effect of chloroquine in COVID-19 patients is still waiting to be seen. Understanding its pharmacokinetics is important in order to study its exposure-efficacy/safety relationship and provide a basis for its dosing regimen. The purpose of this study was to develop a population PK model of CQ based on the literature data as well as the data from COVID-19 patients.

\section{Methods}

\section{Clinical pharmacokinetic study of COVID-19 patients}

An open-label, single-center study (ethical review approval number: PJ-NBEY-KY-2020-063-01) was conducted to assess the safety, efficacy, and pharmacokinetics of CQ in patients with COVID-19. The study was approved by the Ethics Committee of Ningbo Hwamei Hospital, University of Chinese Academy of Sciences (Ningbo, China), and was performed in accordance with the Declaration of Helsinki.

Patients who met the inclusion criteria but did not have any of the exclusion criteria were included in this study. Inclusion criteria included:

1) Being aged 18 years old or older

2) Having been diagnosed with COVID-19 and meeting all of the following criteria: (A) had an epidemiological history, (B) had clinical manifestations (met any two of the following - fever; normal or decreased white blood cell count or lymphopenia in the early stage of onset; and chest radiology in the early stage showing multiple small patchy shadowing and interstitial changes, which is especially significant in periphery pulmonary (furthermore, this develops into bilateral multiple ground-glass opacity and infiltrating shadowing. Pulmonary consolidation occurs in severe cases. Pleural effusion is rare), and (C) suspected cases who had one of the following etiological evidence and had consequently been confirmed as COVID-19: respiratory or blood specimens testing positive for novel coronavirus nucleic acid by real-time fluorescent RT-PCR; respiratory or blood specimen virus gene sequencing had shown them to be highly homologous with the known novel coronavirus.

These patients received CQ phosphate administration unless they had one or more of the following exclusion criteria: 1) female patients in pregnancy, 2) patients with a clear history of allergies to chloroquine, 3 ) patients suffering from diseases of the blood system, 4) patients suffering from chronic liver or kidney diseases and reaching the terminal stage, 5) patients suffering from arrhythmia or chronic heart disease patients, 6) patients with known retinal diseases or hearing loss, 7) patients with known mental illness, and 8) patients who have to use digitalis drugs for existing underlying diseases.

All enrolled subjects signed the Informed Consent Form (ICF) before the study was conducted. Subjects received $500 \mathrm{mg}$ CQ phosphate (300 mg CQ) twice a day for 7 days continuously. Blood samples of $4 \mathrm{ml}$ on days $1,3,7$, and 14 were collected prior to dose administration. Additional sparse blood samples were collected. Anticoagulation of ethylene diamine tetraacetic acid (EDTA) was used to separate plasma after centrifugation for $5 \mathrm{~min}$ at $3000 \mathrm{rpm}$. The collected plasma samples were stored at $-80^{\circ} \mathrm{C}$ before analysis. The plasma concentrations of CQ were determined using a validated highperformance liquid chromatography-tandem mass spectrometry (HPLC-MS/MS) method (see details in supplementary file). The lower limit of quantitation (LLOQ) was $2.00 \mathrm{ng} / \mathrm{ml}$. The accuracy was within the range of $\pm 15 \%$, and the precision was less than $15 \%$.

All subjects receiving at least one dose were incorporated into the analysis. The patient demographics, baseline 
characteristics (including laboratory examination), and drug combination information were also collected and included in the analysis.

\section{Literature data collection}

All published literature on clinical PK of CQ was collected from PubMed and Embase databases. The keywords used for searching were: "Clinical Pharmacokinetic and Chloroquine". Publications from January 1, 1940, to February 29, 2020, were reviewed. Inclusion criteria of publications for PK model development were: 1) the study drug was chloroquine phosphate or chloroquine, 2) human, as the research subjects had participated in clinical trials, 3) the literature reported the plasma CQ concentration-time profiles. Exclusion criteria were: 2) literature did not clearly describe the dosage and the demographics of subjects, 2) the reported CQ concentration-time profiles were too vague for data extraction, 3) literature reported only serum or blood drug concentration instead of plasma concentration.

Aggregate (mean) plasma CQ PK profiles of identified publications were extracted together with the dosing information. The number of subjects that contributed data to each aggregate profile was included as a variable in the analysis dataset. An indicator variable was also created to appoint the PK profiles as either aggregate or individual PK data to allow for separately estimating their residual errors.

\section{Population PK model development}

\section{Structural PK model}

A two-compartment model with first-order oral elimination and absorption with an absorption lag was developed to describe the plasma concentration-time course of CQ (Fig. 1). The same model structure has been used in the literature to describe the PK of CQ [12-14]. The model parameters estimated in the structural PK model included first-order oral absorption (ka), apparent clearance $(\mathrm{CL} / \mathrm{F})$, apparent intercompartmental clearance $(\mathrm{Q} / \mathrm{F})$, volume of distribution for the central compartment (V2/F), volume of distribution for the peripheral compartment(V3/F), and lag-time (ALAG). An exponential error model was used to characterize interindividual variability for each parameter, where possible, assuming log-normal parameter distributions. Residual variability $\left(\sigma^{2}\right)$ for the plasma concentration data was evaluated using separate proportional error models for aggregate data from literature and individual COVID-19 patients. For aggregate profile, the residual error was weighted by the inverse of the square root of the number of individuals that contributed data to an aggregate plasma PK profile [15]. In addition to population model-based meta-analysis, the current suggested methodology for stabilizing pharmacokinetic model when analysis the sparse data is to use the \$PRIOR functionality in NONMEM, which can make the model run successfully by using a priori information $[16,17]$. This methodology was also conducted and compared. The population pharmacokinetic literature about chloroquine on PubMed was searched, and the information then collected and summarized. The meta-analysis of previous population pharmacokinetic studies was conducted, and the summarization of the PK parameters is provided in Table S2 in the supplementary file. The \$PRIOR function of the NONMEM software was then used to rerun the model.

\section{Covariate analysis}

The main purpose of covariate analysis was to investigate the effects of covariates on CL/F and V2/F. Since many covariates were not reported in the literature, the aggregate data from literature and clinical PK data was only used to establish the base model. For covariate analysis, the model parameters were fixed to estimated values from the base model except for parameters of random effects for $\mathrm{CL} / \mathrm{F}$ and $\mathrm{V} 2 / \mathrm{F}$. Then, this model was used to investigate the influence of covariates based on only the PK and covariates data from COVID-19 patients. The demographic data included race, age, and body weight. Baseline laboratory tests of COVID-19 patients were also analyzed, which included alanine aminotransferase (ALT), albumin (ALB), aspartate transaminase (AST), serum
Fig. 1 Chloroquine population pharmacokinetic model structure

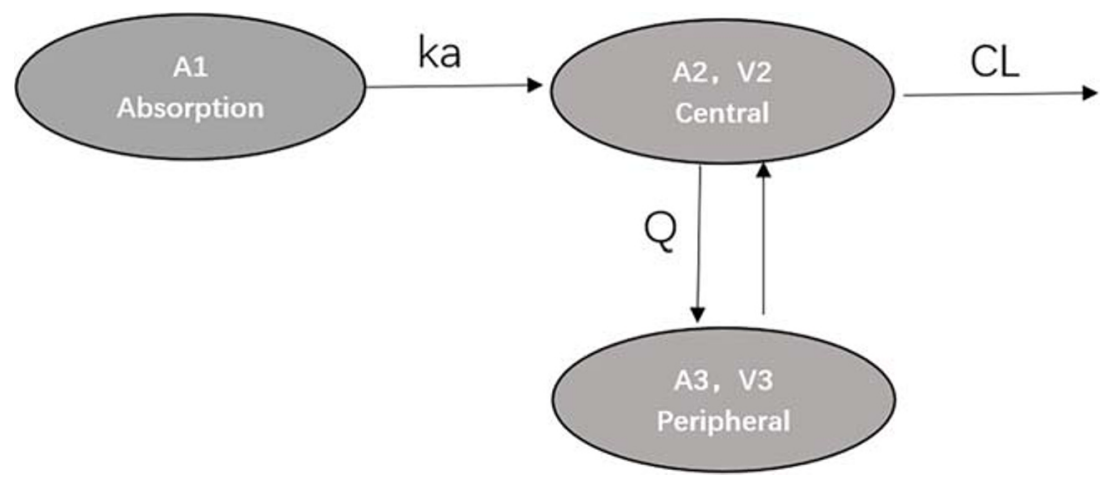


creatinine ( $\mathrm{SCr}$ ), direct bilirubin (DBIL), total bilirubin (TBIL), body temperature baseline (TEMB), highest body temperature in hospital (TEMP), white blood cell count (WBC), blood platelet count (PLT), hemoglobin (HGB), Ddimer, hematocrit (HCT), and creatinine clearance (CrCL). Missing covariates that were less than $5 \%$ of total covariates data were imputed by the median values, while missing covariates that were equal to or greater than $5 \%$ of total covariates data were not included in analysis. The covariates that were evaluated on PK model parameters are summarized in Table S1 in the supplementary file. The covariates were incorporated into the base model using the step-wise screening approach, which was implemented manually through forward selection and backward elimination. Power and proportional covariate models of covariate effects on PK parameters were tested for continuous variables and categorical variables respectively. Potential covariates were entered one by one into the population PK model. When the objective function value (OFV) was reduced by more than 3.84 with degrees of freedom (df) equal to $1(p<0.05)$, the covariate was kept in the model. After the development of a full multivariable model, it was checked by subtracting each covariate individually using backward elimination. Where OFV was increased by more than $6.63(p<0.01, \mathrm{df}=1)$, the subtracted covariate was put back into the model. Allometric scaling models using body weight normalized PK parameters to size were also evaluated [18].

\section{Model evaluation and validation}

The final population PK model was assessed using the goodness-of-fit (GOF) plots, which included the dependent variable (DV) versus individual prediction (IPRED) or population prediction (PRED), conditional weighted residuals (CWRES) versus PRED, and CWRES versus time. Prediction-corrected visual predictive check (pcVPC) [19] was also produced, which was conducted based on simulations of 1000 replicates .

\section{Model simulation}

The simulation of PK profile following various CQ phosphate dosing regimens was conducted using the individual PK parameter values from COVID-19 patients. Different dose regimens of CQ phosphate were under consideration including the standard treatment for antimalarial, the efficacious dose clinically observed [3], and recommended dose according to our previous work on the CQ physiologically based pharmacokinetic (PBPK) study. Five dosing regimens of CQ phosphate (Table 1) were proposed for the treatment of COVID19 patients. The plasma concentration of CQ under five dosing regimens were simulated using the final population PK model. The individual PK parameters of the 50 COVID-19 patients were used to conduct simulations under each dosing scenario. The 5th, 50th, and 95th percentiles of simulated plasma CQ concentrations were plotted over time. Meanwhile, a safety margin was proposed. Chronically treated patients with serum CQ concentration below $1.3 \mu \mathrm{mol} / 1(416 \mathrm{ng} / \mathrm{ml})$ demonstrated no side-effects, but $80 \%$ of patients experienced side-effects when their serum concentration was above $2.5 \mu \mathrm{mol} / 1$ $(800 \mathrm{ng} / \mathrm{ml})[15,19]$. Assuming plasma concentrations are equivalent to serum concentrations, a plasma concentration of $400 \mathrm{ng} / \mathrm{ml}$ was selected as a safety limit, and the warning limit was set at a maximum concentration of $800 \mathrm{ng} / \mathrm{ml}$.

\section{Software and platform used}

Dataset arrangement and exploratory data analysis were performed using R (version 3.5.3, https://www.r-project. org/) and RStudio (version 1.1.453, https://rstudio.com/). A nonlinear mixed-effects model was implemented in NONMEM (version 7.3, Icon Development Solutions,

Table 1 Chloroquine phosphate dosing regimen simulated in Fig. 5

\begin{tabular}{|c|c|c|c|}
\hline No. & Rational & $\begin{array}{l}\text { Dosing regimen for } \\
\text { chloroquine phosphate }\end{array}$ & Reference \\
\hline 1 & $\begin{array}{l}\text { The standard dosing for } \\
\text { the antimalarial } \\
\text { treatment }\end{array}$ & $\begin{array}{l}1000 \mathrm{mg} \text { on day } 1, \\
500 \mathrm{mg} \text { after } 6 \mathrm{~h}, \\
\text { followed by } 500 \mathrm{mg} \\
\text { QD for day } 2 \text { and } 3\end{array}$ & [9] \\
\hline 2 & $\begin{array}{l}\text { The recommended dosing } \\
\text { for the treatment of } \\
\text { COVID-19 patients } \\
\text { (body weight }>50 \mathrm{~kg} \text { ) } \\
\text { from Diagnosis and } \\
\text { Treatment for } \\
\text { COVID-19 (7th ver- } \\
\text { sion) issued by the } \\
\text { China National Health } \\
\text { Commission }\end{array}$ & $500 \mathrm{mg}$ BID for 7 days & [4] \\
\hline 3 & $\begin{array}{l}\text { The recommended dosage } \\
\text { for acute COVID-19 } \\
\text { patients }\end{array}$ & $\begin{array}{c}750 \mathrm{mg} \text { on day } 1,500 \mathrm{mg} \\
\text { after } 6 \mathrm{~h} \text {, followed by } \\
500 \mathrm{mg} \text { QD till day } 5\end{array}$ & {$[25]$} \\
\hline 4 & $\begin{array}{l}\text { The recommended dosage } \\
\text { for moderate } \\
\text { COVID-19 patients }\end{array}$ & $\begin{array}{l}750 \mathrm{mg} \text { on day } 1,500 \mathrm{mg} \\
\text { after } 6 \mathrm{~h} \text {, followed by } \\
500 \mathrm{mg} \text { BID on day } 2 \\
\text { and } 3,250 \mathrm{mg} \text { BID on } \\
\text { day } 4 \text { and } 5\end{array}$ & {$[25]$} \\
\hline 5 & $\begin{array}{l}\text { The recommended dosage } \\
\text { for vulnerable patients } \\
\text { who may need a } \\
\text { reduced dose }\end{array}$ & $250 \mathrm{mg}$ BID for 5 days & {$[25]$} \\
\hline
\end{tabular}

Note: This table is attached to Fig. 5 to clarify the dosing regimen simulated in Fig. 5 
Table 2 Demographic and baseline characteristics (mean \pm SD) of COVID-19 patients who participated in the clinical trial

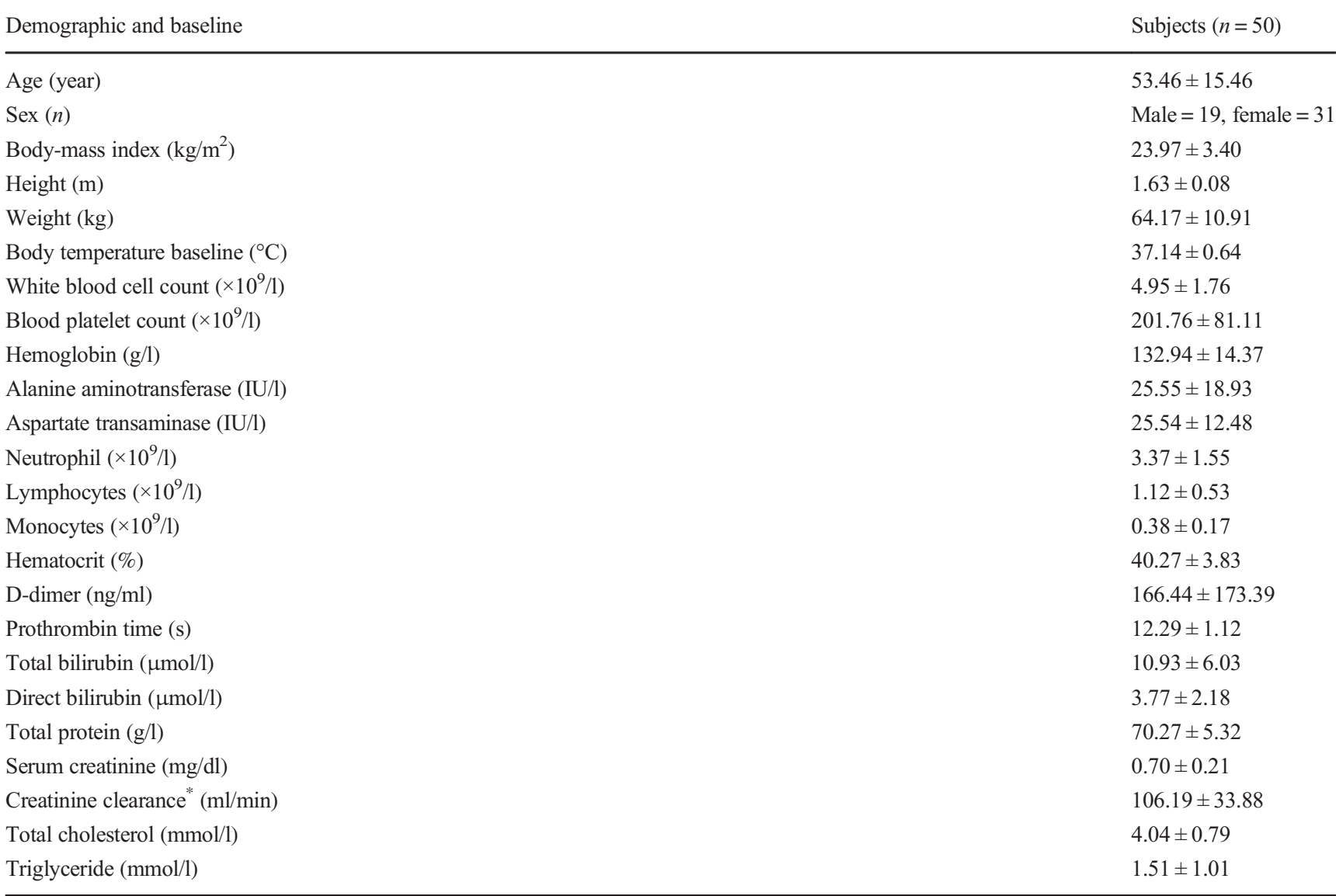

*Creatinine clearance was calculated using Cockcroft-Gault equation

For men, Creatinine clearance $=(140-$ age $) \frac{\times \text { weight }}{72 \times \text { serum creatinine }}$

For women, Creatinine clearance $=0.85 \times(140-$ age $) \frac{\times \text { weight }}{72 \times \text { serum creatinine }}$

Ellicott City, MD, USA) interfaced by Pirana (version 2. 8) and Perl speaks NONMEM (PsN) (version 3.6.2) toolkit [20]. Model-based simulations were conducted using the $\mathrm{R}$ mrgsolve package. CQ mean concentrationtime profiles were extracted using Plot Digitizer (GetData, Version 2.26).

\section{Results}

\section{Clinical PK study}

A total of 50 COVID-19 patients (19 males and 31 females) who received $500 \mathrm{mg}$ CQ phosphate (300 mg CQ) for at least one dose were included in analysis. Demographic and baseline characteristics of COVID-19 patients are summarized in Table 2. A total of 315 PK observations from patients were managed in the dataset, and 15 observed concentrations were below the limit of quantification. The trough CQ concentrations (standard deviation) at day 1 , day 3 , day 7 , and day 14 were 117.3 (50.7), 291.5 (45.5), 280.5 (27.5), and 199.3 (65.2) $\mathrm{ng} / \mathrm{ml}$ respectively.

\section{Summary of the literature data}

Extracted from literature, additional CQ PK data were obtained from 18 published literature reports (Table 3). One study on healthy children and Kwashiorkor children, one study on pregnant women, one study on patients with Acute vivax malaria, and nine studies on healthy subjects were included in the meta-analysis. In addition, $18 \mathrm{CQ}$ mean concentration-time profiles were extracted. The dose of $\mathrm{CQ}$ ranged from $50 \mathrm{mg}$ to $600 \mathrm{mg}$, and contained a single-dose administration and multiple-dose administrations (e.g., once a day or 
Table 3 Summary of published literature reports on chloroquine pharmacokinetics

\begin{tabular}{|c|c|c|c|c|c|c|}
\hline $\begin{array}{l}\text { Study } \\
\text { number }\end{array}$ & Reference & $\begin{array}{l}\text { Studied } \\
\text { population }\end{array}$ & $\begin{array}{l}\text { Chloroquine } \\
\text { doses }\end{array}$ & $\begin{array}{l}\text { Number of } \\
\text { treatment periods }\end{array}$ & $\begin{array}{l}\text { Number of } \\
\text { individuals } \\
\text { generated }\end{array}$ & $\begin{array}{l}\text { Data } \\
\text { points }\end{array}$ \\
\hline \multirow[t]{2}{*}{1} & \multirow[t]{2}{*}{$\begin{array}{l}\text { Walker O et al., } \\
1987\end{array}$} & $\begin{array}{r}\text { Children } \\
(n=6)\end{array}$ & $10 \mathrm{mg} / \mathrm{kg}$ & 1 (single oral dose) & 1 & 12 \\
\hline & & $\begin{array}{l}\text { Kwashiorkor } \\
\text { Children } \\
(n=5)\end{array}$ & $10 \mathrm{mg} / \mathrm{kg}$ & 1 (single oral dose) & 1 & 11 \\
\hline \multirow[t]{2}{*}{2} & \multirow[t]{2}{*}{$\begin{array}{l}\text { Harin A et al., } \\
2010\end{array}$} & $\begin{array}{l}\text { Pregnant } \\
\quad(n=30)\end{array}$ & $450 \mathrm{mg}$ & $\begin{array}{l}1 \text { (oral daily dose } \\
\text { for } 3 \text { days) }\end{array}$ & 1 & 6 \\
\hline & & $\begin{array}{l}\text { Healthy } \\
\qquad(n=30)\end{array}$ & $450 \mathrm{mg}$ & $\begin{array}{l}1 \text { (oral daily dose } \\
\text { for } 3 \text { days) }\end{array}$ & 1 & 6 \\
\hline 3 & $\begin{array}{l}\text { Gustafsson LL } \\
\text { et al., } 1983\end{array}$ & $\begin{array}{l}\text { Healthy } \\
\qquad(n=11)\end{array}$ & $300 \mathrm{mg}$ & 1 (single oral dose) & 1 & 18 \\
\hline 4 & $\begin{array}{r}\text { Neuvonen PJ } \\
\text { et al., } 2009\end{array}$ & Healthy $(n=6)$ & $310 \mathrm{mg}$ & 1 (single oral dose) & 1 & 9 \\
\hline 5 & $\begin{array}{l}\text { Pukrittayakame } \\
\text { S et al., } 2014\end{array}$ & $\begin{array}{l}\text { Healthy } \\
\qquad(n=16)\end{array}$ & $600 \mathrm{mg}$ & 1 (single oral dose) & 1 & 19 \\
\hline 6 & $\begin{array}{l}\text { Walker O et al., } \\
1987\end{array}$ & Healthy $(n=8)$ & $600 \mathrm{mg}$ & 1 (single oral dose) & 1 & 12 \\
\hline 7 & $\begin{array}{l}\text { de Vries PJ } \\
\text { et al., } 1994\end{array}$ & $\begin{array}{l}\text { Healthy } \\
\qquad(n=19)\end{array}$ & $600 \mathrm{mg}$ & 1 (single oral dose) & 1 & 17 \\
\hline \multirow[t]{2}{*}{8} & \multirow[t]{2}{*}{$\begin{array}{l}\text { Oosterhuis B } \\
\text { et al., } 1981\end{array}$} & Healthy $(n=3)$ & $\begin{array}{l}600 \text { then } \\
300 \mathrm{mg}\end{array}$ & $\begin{array}{l}1 \\
\quad(600-600-300 \\
\mathrm{mg} \text { at } \mathrm{t}=0, \\
24 \text { and } 48 \mathrm{~h})\end{array}$ & 1 & 17 \\
\hline & & Healthy $(n=2)$ & $\begin{array}{l}600 \text { then } \\
300 \mathrm{mg}\end{array}$ & $\begin{array}{l}(600-600-300 \\
\text { mg at } t=0,\end{array}$ & 1 & 17 \\
\hline \multirow[t]{2}{*}{9} & \multirow[t]{2}{*}{$\begin{array}{l}\text { Onyeji CO et al. } \\
2001\end{array}$} & $\begin{array}{l}\text { Healthy } \\
\qquad(n=18)\end{array}$ & $600 \mathrm{mg}$ & $\begin{array}{l}24 \text { and } 48 \mathrm{~h} \text { ) } \\
1 \text { (single oral dose) }\end{array}$ & 1 & 9 \\
\hline & & $\begin{array}{l}\text { Healthy } \\
\qquad(n=18)\end{array}$ & $600 \mathrm{mg}$ & 1 (single oral dose) & 1 & 9 \\
\hline 10 & $\begin{array}{l}\text { Daher A et al., } \\
\quad 2019\end{array}$ & $\begin{array}{l}\text { Acute vivax } \\
\text { malaria } \\
(n=58)\end{array}$ & $\begin{array}{l}600 \text { then } \\
450 \mathrm{mg}\end{array}$ & $\begin{array}{c}1(600 \mathrm{mg} \text { on day } \\
1, \text { and } 450 \mathrm{mg} \\
\text { on days } 2 \text { and } 3)\end{array}$ & 1 & 6 \\
\hline 11 & $\begin{array}{l}\text { Onyeji CO } \\
\quad \text { et al., } 1993\end{array}$ & Healthy $(n=6)$ & $300 \mathrm{mg}$ & 1 (single oral dose) & 1 & 9 \\
\hline \multirow[t]{3}{*}{12} & \multirow[t]{3}{*}{$\begin{array}{l}\text { Wetsteyn JCFM } \\
\text { et al., } 1995\end{array}$} & Healthy $(n=5)$ & $300 \mathrm{mg}$ & $\begin{array}{l}1 \text { ( } 3 \text { weeks: once } \\
\text { weekly } 300 \mathrm{mg} \text { ) }\end{array}$ & 1 & 13 \\
\hline & & Healthy $(n=4)$ & $200 \mathrm{mg}$ & 1 (3 weeks: twice & 1 & 15 \\
\hline & & Healthy $(n=5)$ & $50 \mathrm{mg}$ & $\begin{array}{l}\text { weekly } 200 \mathrm{mg} \text { ) } \\
1 \text { ( } 3 \text { weeks: once } \\
\text { daily } 50 \mathrm{mg} \text { ) }\end{array}$ & 1 & 15 \\
\hline Total & & & & & 18 & 220 \\
\hline
\end{tabular}

once a week). A total of 220 PK data points from the literature were included in the dataset.

\section{Model development and evaluation}

A two-compartment model with first-order oral absorption and elimination (Fig. 1) best described the CQ plasma concentration. The $\mathrm{CL} / \mathrm{F}$ of CQ was estimated to be $33.3 \mathrm{l} / \mathrm{h}$, absorption rate ka was estimated to be $0.559 \mathrm{~h}^{-1}$, and ALAG was estimated to be $0.149 \mathrm{~h}$. The volume of distribution in central and peripheral compartments was 36301 and 51201 respectively. Inter-compartment clearance $\mathrm{Q} / \mathrm{F}$ was estimated to be $58.7 \mathrm{l} / \mathrm{h}$. The inter-individual variability (IIV) was estimated for ka, CL/F, V2/F, V3/F, and Q/F. Due to the high inter-individual variability of COVID-19 patients and the inter-studies variability, the IIV for PK parameters were expressed as CV\% and ranged from $44.8 \%$ to $67.7 \%$, except for IIV of $\mathrm{ka}(110.5 \%)$. The RSE\% of fixed- and randomeffect parameter estimates were less than $40 \%$. The results for \$PRIOR functionality in NONMEM were shown in the 
Table 4 Model parameter estimation for meta-analysis and observed data

\begin{tabular}{llll}
\hline Parameter & Final estimate & \% RSE & Bootstrap median (95 CI\%) \\
\hline $\mathrm{CL} / \mathrm{F}(1 / \mathrm{h})$ & 33.3 & 8.00 & $33.7(29.2,38.6)$ \\
$\mathrm{V} 2 / \mathrm{F}(\mathrm{l})$ & 3630 & 13.3 & $3598(2521,4532)$ \\
$\mathrm{Q} / \mathrm{F}(\mathrm{h} / \mathrm{h})$ & 58.7 & 15.4 & $56.0(43.7,72.0)$ \\
$\mathrm{V} 3 / \mathrm{F}(\mathrm{l})$ & 5120 & 11.8 & $5044(4274,6089)$ \\
$\mathrm{ka}\left(\mathrm{h}^{-1}\right)$ & 0.559 & 20.2 & $0.607(0.370,1.12)$ \\
ALAG1 $(\mathrm{h})$ & 0.149 & 20.4 & $0.149(0.130,0.320)$ \\
Weight on CL/F & $0.75 \mathrm{FIX}$ & $/$ & $/$ \\
Weight on V2/F & $1 \mathrm{FIX}$ & $/$ & $/$ \\
$\omega^{2}$ for CL/F & 48.8 & 8.50 & $47.4(35.8,61.3)$ \\
$\omega^{2}$ for V2/F & 67.7 & 14.0 & $67.6(49.8,88.5)$ \\
$\omega^{2}$ for Q/F & 48.4 & 26.1 & $46.8(21.8,63.8)$ \\
$\omega^{2}$ for V3/F & 48.2 & 18.4 & $48.1(27.8,63.8)$ \\
$\omega^{2}$ for ka & 111 & 40.5 & $106(54.8,139)$ \\
$\sigma^{2}$ for individual data & 24.7 & 4.20 & $24.7(19.4,28.4)$ \\
$\sigma^{2}$ for aggregate data & 59.7 & 4.60 & $58.6(48.1,72.5)$ \\
\hline
\end{tabular}

IIVs $\left(\omega^{2}\right)$ and residual errors $\left(\sigma^{2}\right)$ are expressed as coefficients of variation (\%)

following Table S3 and Fig. S1 in the supplementary file. As a result, the parameters estimated by the model are close to the results obtained by our previous method, but the RSE\% values of ka and ALAG1 were very large and were not met the acceptable criteria.

During covariate analysis, no demographic or laboratory examination baseline variates were identified to have a significant effect on CQ PK. Since body weight has been identified as a significant covariate for CQPK [12], positive relationship of body weight on $\mathrm{CL} / \mathrm{F}$ and $\mathrm{V} 2 / \mathrm{F}$ was integrated into the PK model, and the decrease objective function value was 14.1 (corresponding to a $p$ value of 0.01 ). The final model included body weight and used a fixed allometric coefficient of 0.75 for $\mathrm{CL} / \mathrm{F}$ and 1 for V2/F [12]. The final model parameters estimates are summarized in Table 4 . The condition number of the final model was 52.8 .
Fig. 2 Goodness of fit plots for the final model. The blue dots represent the aggregate data. The red dots represent the data from individual COVID-19 patients. The black solid line represents a linear smooth line. The gray diagonal lines (top panels) and horizontal lines (bottom panels) are the lines of identity and zero lines respectively
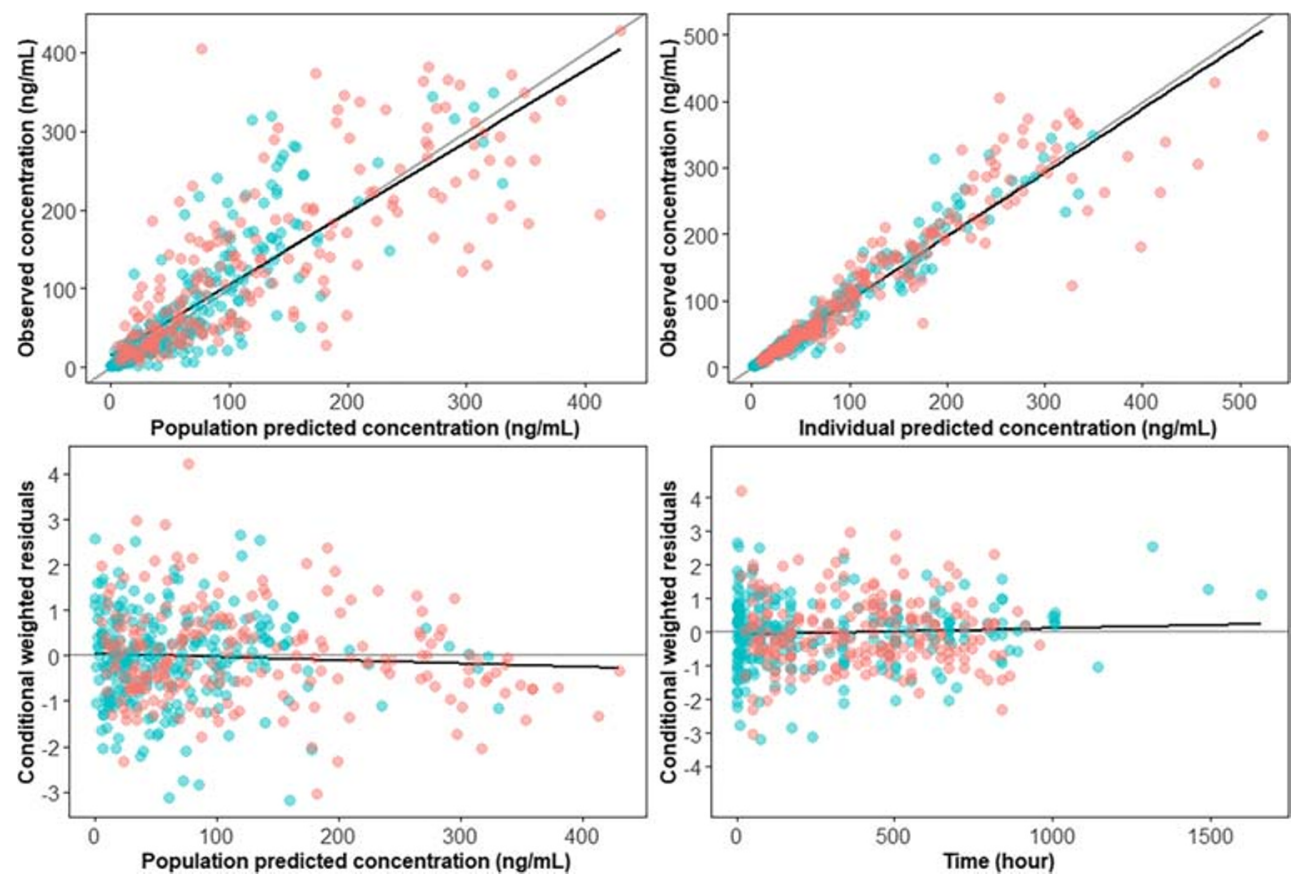

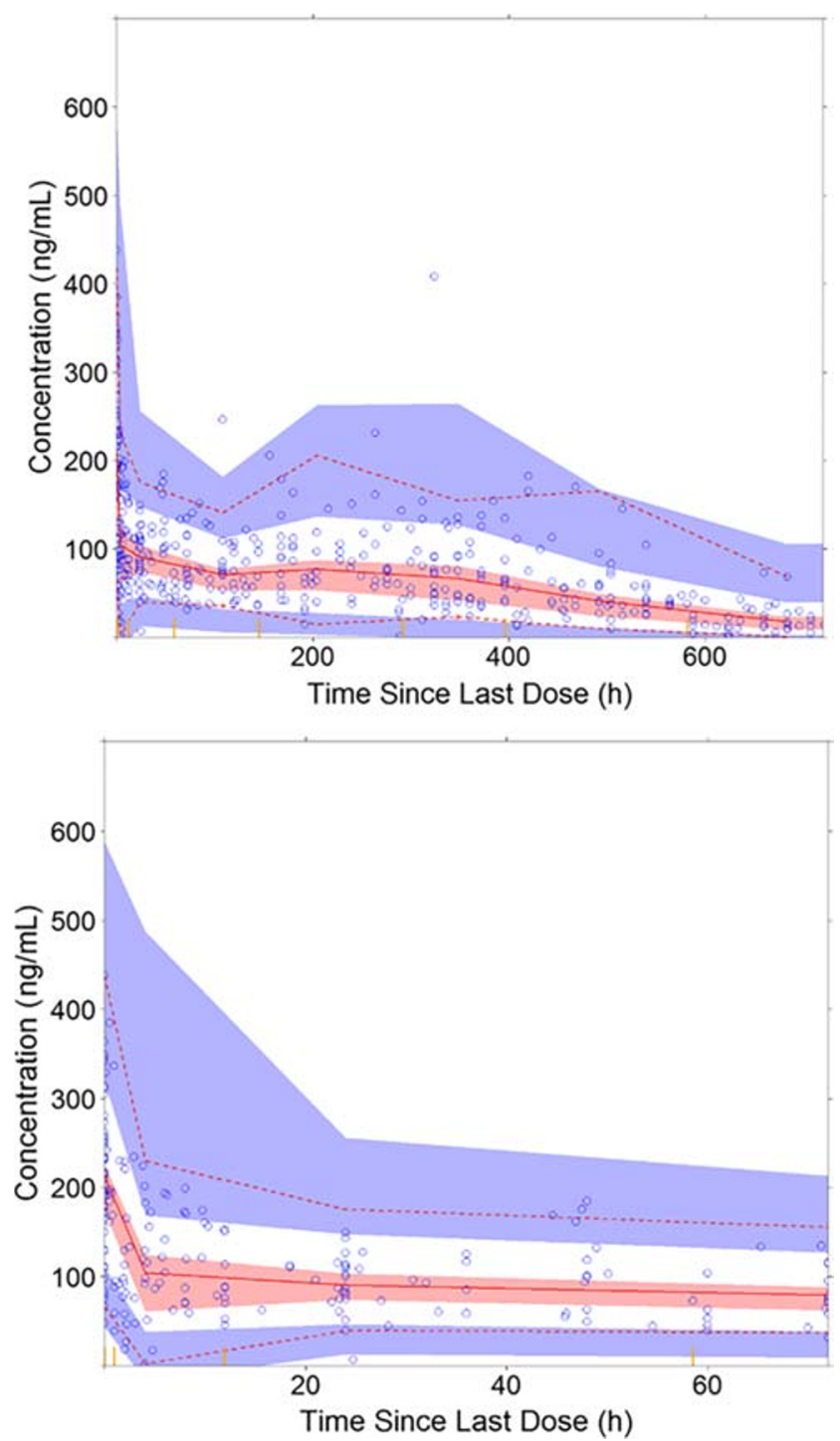

Fig. 3 Prediction-corrected VPC (pcVPC) of the final model. The top panel represents pcVPC plot of 0-720 h; the bottom panel represents pcVPC plot of 0-72 h. The blue circles represent chloroquine concentration data. The upper red dotted line, the middle red solid line, and the lower red dotted line represent $95 \%, 50 \%$, and $5 \%$ quantiles of observed data respectively. The shaded area represents a $90 \%$ confidence interval for $95 \%, 50 \%$, and $5 \%$ quantiles of observed data

As depicted in Fig. 2, GOF plots of the population- and individual- predicted plasma CQ concentrations versus observed concentrations showed no major bias. The conditional weighted residuals (CWRES) versus population-predicted concentrations or versus time after dose showed that most of CWRES were within the range of $(-2,2)$. The pcVPC revealed that there was reasonable agreement between the observed and model-predicted concentrations over time (Fig. 3). Figure 4 shows the time-course of observed versus individual predicted plasma CQ concentrations from nine representative patients. Overall, these model diagnostics suggest that the final population PK model adequately describes the CQ plasma data.

\section{Model simulation}

The simulated CQ median concentrations with $90 \%$ predictive interval under five dosing regimens were shown in Fig. 5. The simulation results show that the predicted population mean and individual $\mathrm{C}_{\max }$ of regimen 1 (conventional antimalarial treatment), regimen 2 , and regimen 5 were below $400 \mathrm{ng} / \mathrm{ml}$. Under regimen 2, the model simulated population median $\mathrm{C}_{\max }$ of plasma exceeded $400 \mathrm{ng} / \mathrm{ml}$, but was below $800 \mathrm{ng} / \mathrm{ml}$. The simulated population median $\mathrm{C}_{\max }$ of regimen 3 was below $400 \mathrm{ng} / \mathrm{ml}$, while 95th percentile of simulated plasma CQ concentrations slightly exceeded $400 \mathrm{ng} / \mathrm{ml}$, but was below $800 \mathrm{ng} / \mathrm{ml}$.

\section{Discussion}

Characterization of the PK of CQ in COVID-19 patients is essential to evaluate the exposure-safety/efficacy relationship of CQ and subsequent dosing regimen optimization. However, traditional PK analysis is not possible with the current study because only sparse PK samples are available. Thus, we developed a population-based PK model based on both the meta-individual from the literature and the individual patient in the study. Such a method has been applied in the literature to address critical gaps in experimental PK data, especially when the PK of the drug has been extensively studied [21, 22]. The developed PK model allows us to obtain individual PK parameters for each patient and predict their exposure metrics in the trial.

A two-compartment model with first-order absorption best describes the time course of CQ in patients. This is consistent with other publications on PK modeling of CQ for various patient populations including children, pregnant women, healthy adults, and malaria patients [12-14, 23]. The estimated fixed-effect PK parameter generally agrees with those from other publications. Body weight has been included as a significant covariate for CQ clearance and volume of distribution, because the previous publication has identified body weight as a significant covariate for CQ PK [12]. We think that using the functionality in NONMEM, the results were unacceptable for the following reasons: 1).the number of literature studies $(n=5)$ that met the requirements was small, which cannot provide sufficient prior information, 2) the subject type in the literature was inconsistent, including healthy subjects, infants, and pregnant women, and 3) there was a 10fold difference on the same PK parameter among the five studies, meaning that there was a large inconsistency among the prior information. Therefore, we think that our current approach was more appropriate for establishing a population pharmacokinetic model of chloroquine in COVID-19 patients. 

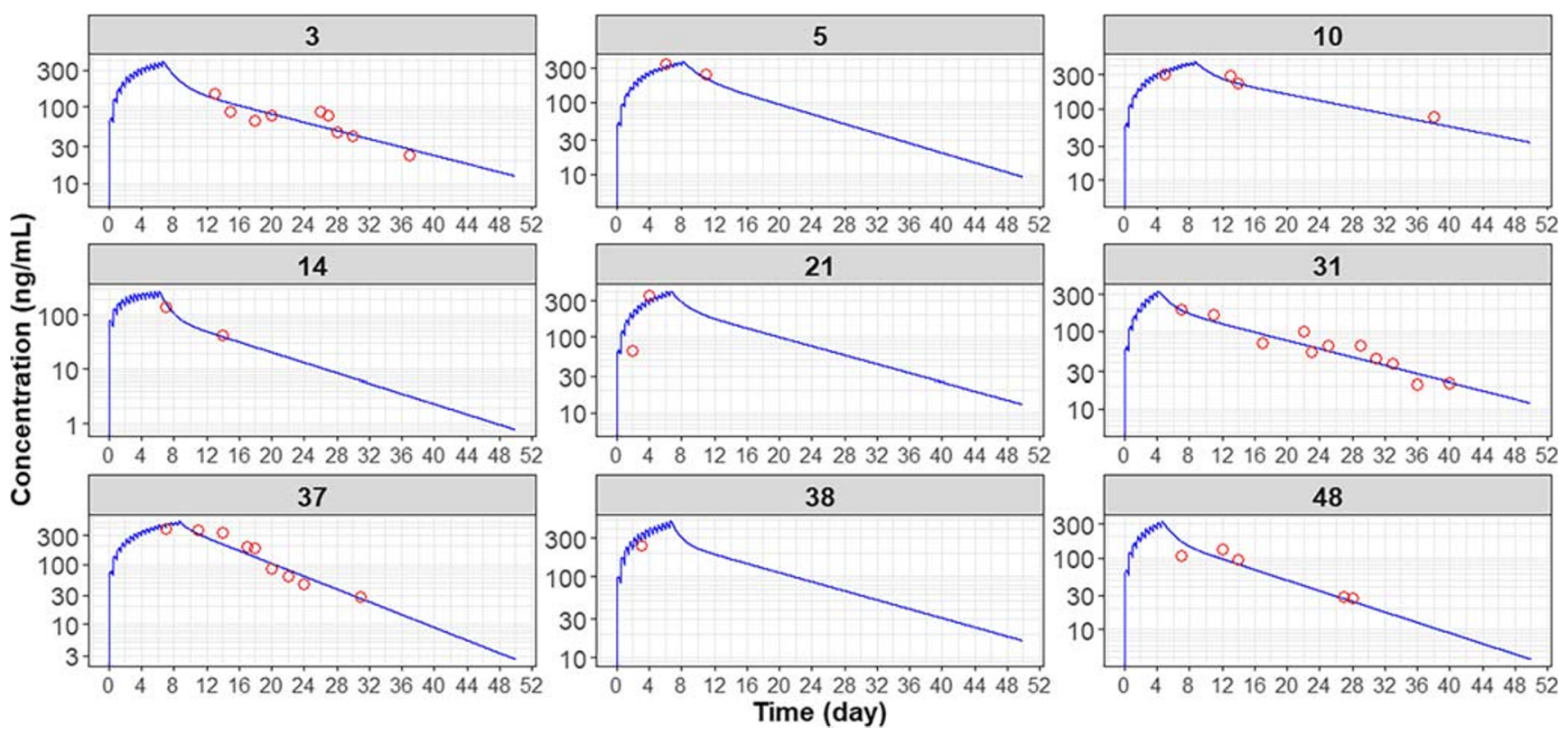

Fig. 4 Observed vs individual predicted plasma concentration for selected subjects

The safety of CQ has been always a major concern in clinical treatment, especially at high drug concentrations. The chronically treated patients with serum CQ concentration below $1.3 \mu \mathrm{mol} / \mathrm{l}(416 \mathrm{ng} / \mathrm{ml})$ demonstrated no side-effects, but $80 \%$ of patients experienced side-effects when their serum concentration was above $2.5 \mu \mathrm{mol} / \mathrm{l}(800 \mathrm{ng} / \mathrm{ml})[24,25]$. A retrospective study found that ingestion of more than $5 \mathrm{~g} \mathrm{CQ}$ caused severe CQ poisoning and fatal outcome, where CQ blood concentration was more than $25 \mu \mathrm{mol} / \mathrm{l}$, corresponding to the plasma CQ concentration of $3.5 \mu \mathrm{mol} / \mathrm{l}(1120 \mathrm{ng} / \mathrm{ml})$ [26]. For a conservative safety margin, a safe plasma concentration of $400 \mathrm{ng} / \mathrm{ml}$ and a vigilant plasma concentration of $800 \mathrm{ng} / \mathrm{ml}$ was selected.

Model-based simulations were conducted to evaluate the PK profile under various dosing regimens (Fig. 5). The results are generally consistent with the previous prediction using the PBPK model approach for the same dosing regimens [27]. The simulation results from regimens 1 and 3 show that the loading dose is effective in achieving a faster onset of drug exposure. Also, the concentrations at various dosing regimens are below the $800 \mathrm{ng} / \mathrm{ml}$ threshold, indicating that these regimens are generally safe. Based on the simulation results (Fig.

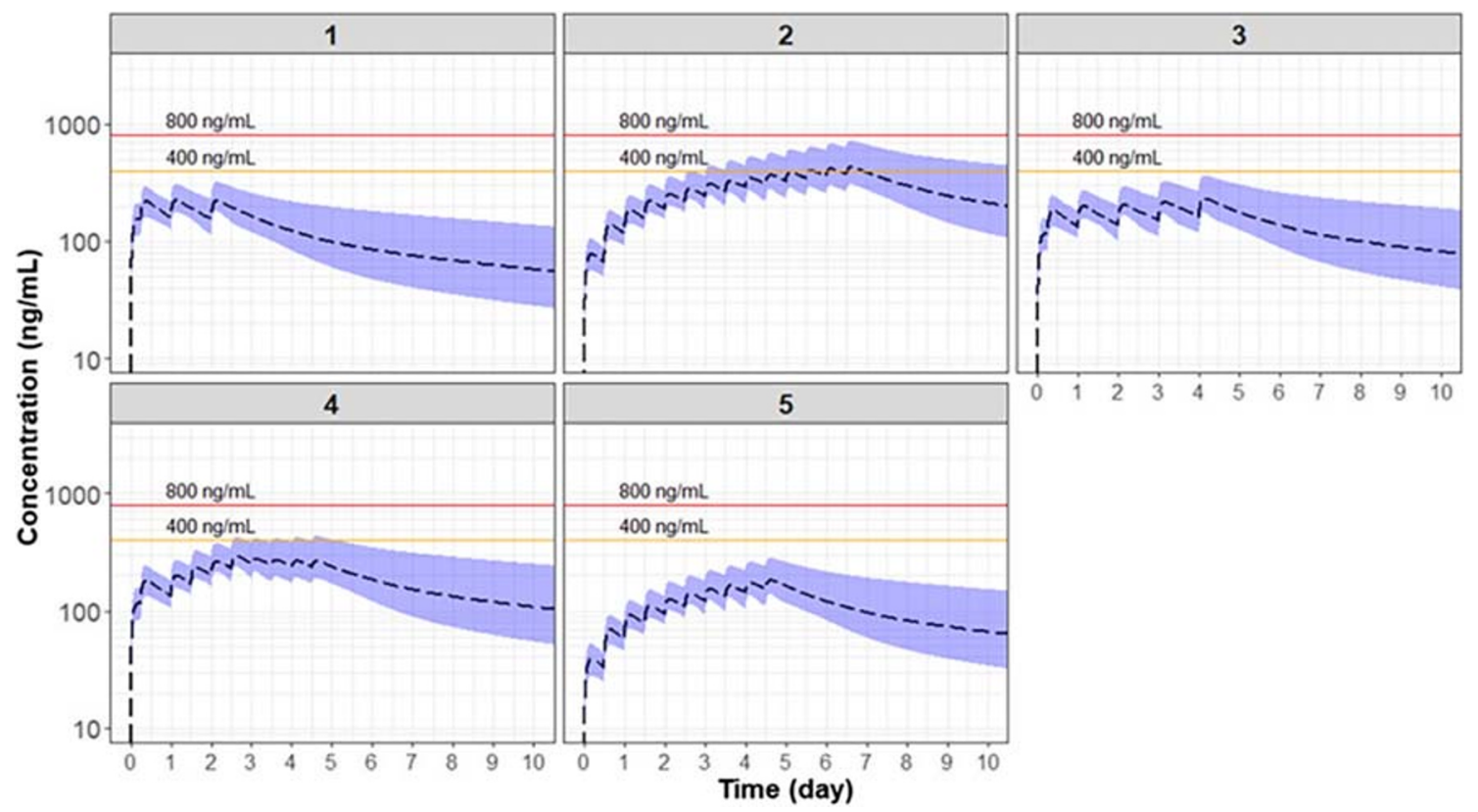

Fig. 5 Simulations of chloroquine PK under various dosing regimens. The black dashed line represents the 50th percentile and the shaded area represents the range between 5th and 95th percentile. The solid line represents the safety concentration threshold of $400 \mathrm{mg} / \mathrm{ml} \mathrm{and} 800 \mathrm{mg} / \mathrm{ml}$ 
5), the maximum CQ plasma concentration in all designed dosing regimens was below the vigilant threshold, except for regimen 2 . The rest of the regimens yielded concentrations below $400 \mathrm{ng} / \mathrm{ml}$.

The therapeutic concentration of CQ in COVID-19 patients has not yet been established. The reported in-vitro $\mathrm{EC}_{50}$ of chloroquine inhibiting SARS-CoV-2 virus ranges from 1.13 to $23.9 \mu \mathrm{mol} / \mathrm{l}$ (corresponding to 362 to $7646 \mathrm{ng} / \mathrm{ml}$ ) $[1,2,28]$. This concentration represents the free drug concentration in the medium. Based on Fig. 5, the plasma CQ concentration appears to be lower than the reported in-vitro $\mathrm{EC}_{50}$ at these dosing regimens. Considering about $55 \%$ of the chloroquine in the plasma is bound to protein [6], the gap between free drug concentration in plasma and in-vitro $\mathrm{EC}_{50}$ is even bigger. However, it should be noted that the in-vitro $\mathrm{EC}_{50}$ should be compared to the drug concentration in the interstitial fluid or intracellular fluid in the lungs, which is not available. However, it is known that chloroquine is heavily accumulated in the lungs [29]. Furthermore, the mechanism of chloroquine against COVID-19 is still unclear. Chloroquine may achieve the therapeutic effect via pathways other than directly inhibiting the virus. Savarino et al. hypothesized that CQ might inhibit the production of pro-inflammatory cytokines (such as interleukin-6), thereby blocking the pathway that leads to acute respiratory distress syndrome [30]. Nevertheless, the in-vivo effective concentration of CQ remains to be defined. Future PK/PD analysis based on various biomarkers and clinical endpoints is warranted.

The current analysis is not without limitation. For instance, because the number of patients, concentrations, and covariate data in COVID-19 patients were limited, it might be difficult to identify significant covariate effects, if there is any. The gene polymorphism of CYP2C8, one of the main metabolic enzymes of CQ, was also not evaluated because the data was not available. In summary, a population PK model for CQ was developed using a population-based meta-analysis approach. The model was constructed using combined PK data from the meta-individual in the literature and individual COVID-19 patients, which provides confidence that this model can reasonably characterize CQ PK in the patient population. The derived population PK model should allow for the assessment of PK-PD relationships for CQ when given alone or in combination with other agents to treat COVID-19.

Supplementary Information The online version contains supplementary material available at https://doi.org/10.1007/s00228-020-03032-6.

Acknowledgments We would like to sincerely thank the people who participated in this study, and all the medical staff in HwaMei hospital who helped conduct this clinical pharmacokinetic trial.

Authors' contributions Dongyang Liu conceived and designed research; Xiaoyu Yan designed and developed the population pharmacokinetic model, and guided the manuscript writing; Shun Zhang designed the clinical pharmacokinetic study; Haiyan Li directed the whole study; and
Xueting Yao and Xiaohan Wang conducted the model analysis and prepared the manuscript. Cheng Cui designed dosing regimens. Ting Cai, Jing Lin, Zi Xiong assayed the clinical pharmacokinetic data. Xiaoxu Wang, Zhe Hou and Qi Liu assayed the collected data.

Funding This study was supported by the Ministry of Science and Technology (MOST) of the People's Republic of China foundation for SARS-nCov-2 Research (grant No. 2020YFC0844500) and the Bill \& Melinda Gates Foundation (grant No. INV-015694).

Data Availability All data used in this study were reported in the manuscript.

\section{Compliance with ethical standards}

Conflict of interest The authors have no conflict of interest to disclose.

Ethics approval A clinical pharmacokinetic study was approved by the Ethics Committee of Ningbo Hwamei Hospital, University of Chinese Academy of Sciences (Ningbo, China) (ethical review approval number: PJ-NBEY-KY-2020-063-01).

Consent to participate All enrolled subjects signed the Informed Consent Form (ICF) before the study was conducted.

Consent for publication All co-authors have reviewed and approved this manuscript for publication.

Code availability The NONMEM code was provided in the supplementary file.

Supplementary Information The online version contains supplementary material available at https://doi.org/10.1007/s00228-020-03032-6.

Open Access This article is licensed under a Creative Commons Attribution 4.0 International License, which permits use, sharing, adaptation, distribution and reproduction in any medium or format, as long as you give appropriate credit to the original author(s) and the source, provide a link to the Creative Commons licence, and indicate if changes were made. The images or other third party material in this article are included in the article's Creative Commons licence, unless indicated otherwise in a credit line to the material. If material is not included in the article's Creative Commons licence and your intended use is not permitted by statutory regulation or exceeds the permitted use, you will need to obtain permission directly from the copyright holder. To view a copy of this licence, visit http://creativecommons.org/licenses/by/4.0/.

\section{References}

1. Yao X, Ye F, Zhang M, Cui C, Huang B, Niu P, Liu X, Zhao L, Dong E, Song C, Zhan S, Lu R, Li H, Tan W, Liu D (2020) In vitro antiviral activity and projection of optimized dosing design of hydroxychloroquine for the treatment of severe acute respiratory syndrome coronavirus 2 (SARS-CoV-2). Clin Infect Dis 71(15): 732-739. https://doi.org/10.1093/cid/ciaa237

2. Wang M, Cao R, Zhang L, Yang X, Liu J, Xu M, Shi Z, Hu Z, Zhong W, Xiao G (2020) Remdesivir and chloroquine effectively inhibit the recently emerged novel coronavirus (2019-nCoV) 
in vitro. Cell Res 30(3):269-271. https://doi.org/10.1038/s41422020-0282-0

3. Gao J, Tian Z, Yang X (2020) Breakthrough: chloroquine phosphate has shown apparent efficacy in treatment of COVID-19 associated pneumonia in clinical studies. Biosci Trends 14(1):72-73. https://doi.org/10.5582/bst.2020.01047

4. Chinese Clinical Guidance for COVID-19 Pneumonia Diagnosis and Treatment (7th edition) (2020) http://kjfy.meetingchina.org/ msite/news/show/cn/3337.html. Accessed 4 May 2020

5. Administration TUSFaD (2020) Fact sheet for health care providers. Emergency use authorization (EUA) of chloroquine phosphate supplied from the Strategic National Stockpile for treatment of Covid-19 In certain hospitalized patients. FDA, Rockville Maryland

6. Ducharme J, Farinotti R (1996) Clinical pharmacokinetics and metabolism of chloroquine. Focus on recent advancements. Clin Pharmacokinet 31(4):257-274. https://doi.org/10.2165/00003088199631040-00003

7. Projean D, Baune B, Farinotti R, Flinois JP, Beaune P, Taburet AM, Ducharme J (2003) In vitro metabolism of chloroquine: identification of CYP2C8, CYP3A4, and CYP2D6 as the main isoforms catalyzing $\mathrm{N}$-desethylchloroquine formation. Drug Metab Dispos 31(6):748-754. https://doi.org/10.1124/dmd.31.6.748

8. Colson P, Rolain JM, Raoult D (2020) Chloroquine for the 2019 novel coronavirus SARS-CoV-2. Int J Antimicrob Agents 55(3): 105923. https://doi.org/10.1016/j.ijantimicag.2020.105923

9. Sanofi-Aventis U.S. LLC (2017) ARALEN (chloroquine phosphate) [package insert]. Sanofi-aventis U.S. LLC, Bridgewater, NJ

10. White NJ (2007) Cardiotoxicity of antimalarial drugs. Lancet Infect Dis 7(8):549-558. https://doi.org/10.1016/s1473-3099(07)70187-1

11. Sánchez-Chapula JA, Navarro-Polanco RA, Culberson C, Chen J, Sanguinetti MC (2002) Molecular determinants of voltagedependent human ether-a-go-go related gene (HERG) K+ channel block. J Biol Chem 277(26):23587-23595. https://doi.org/10.1074/ jbc.M200448200

12. Zhao Q, Tensfeldt TG, Chandra R, Mould DR (2014) Population pharmacokinetics of azithromycin and chloroquine in healthy adults and paediatric malaria subjects following oral administration of fixed-dose azithromycin and chloroquine combination tablets. Malar J 13:36. https://doi.org/10.1186/1475-2875-13-36

13. Hoglund R, Moussavi Y, Ruengweerayut R, Cheomung A, Abelo A, Na-Bangchang K (2016) Population pharmacokinetics of a three-day chloroquine treatment in patients with plasmodium vivax infection on the Thai-Myanmar border. Malar J 15:129. https://doi. org/10.1186/s12936-016-1181-1

14. Salman S, Baiwog F, Page-Sharp M, Kose K, Karunajeewa HA, Mueller I, Rogerson SJ, Siba PM, Ilett KF, Davis TME (2017) Optimal antimalarial dose regimens for chloroquine in pregnancy based on population pharmacokinetic modelling. Int J Antimicrob Agents 50(4):542-551. https://doi.org/10.1016/j.ijantimicag.2017. 05.011

15. Ahn JE, French JL (2010) Longitudinal aggregate data modelbased meta-analysis with NONMEM: approaches to handling within treatment arm correlation. J Pharmacokinet Pharmacodyn 37(2): 179-201. https://doi.org/10.1007/s10928-010-9152-6

16. Chan Kwong AHP, Calvier EAM, Fabre D, Gattacceca F, Khier S (2020) Prior information for population pharmacokinetic and pharmacokinetic/pharmacodynamic analysis: overview and guidance with a focus on the NONMEM PRIOR subroutine. J Pharmacokinet Pharmacodyn 47:431-446. https://doi.org/10. 1007/s10928-020-09695-z

17. Milosheska D, Lorber B, Vovk T, Kastelic M, Dolzan V, Grabnar I (2016) Pharmacokinetics of lamotrigine and its metabolite N-2- glucuronide: influence of polymorphism of UDPglucuronosyltransferases and drug transporters. Br J Clin Pharmacol 82(2):399-411. https://doi.org/10.1111/bcp.12984

18. Anderson BJ, Woollard GA, Holford NH (2000) A model for size and age changes in the pharmacokinetics of paracetamol in neonates, infants and children. Br J Clin Pharmacol 50(2):125-134. https://doi.org/10.1046/j.1365-2125.2000.00231.x

19. Bergstrand M, Hooker AC, Wallin JE, Karlsson MO (2011) Prediction-corrected visual predictive checks for diagnosing nonlinear mixed-effects models. AAPS J 13(2):143-151. https://doi. org/10.1208/s12248-011-9255-Z

20. Lindbom L, Ribbing J, Jonsson EN (2004) Perl-speaks-NONMEM (PsN) - a Perl module for NONMEM related programming. Comput Methods Prog Biomed 75(2):85-94. https://doi.org/10. 1016/j.cmpb.2003.11.003

21. Dolton MJ, D'Argenio DZ (2017) Population-based meta-analysis of roxithromycin pharmacokinetics: dosing implications of saturable absorption and protein binding. J Antimicrob Chemother 72(4): 1129-1136. https://doi.org/10.1093/jac/dkw553

22. Van Wart SA, Shoaf SE, Mallikaarjun S, Mager DE (2013) Population-based meta-analysis of hydrochlorothiazide pharmacokinetics. Biopharm Drug Dispos 34(9):527-539. https://doi.org/10. 1002/bdd. 1863

23. Obua C, Hellgren U, Ntale M, Gustafsson LL, Ogwal-Okeng JW, Gordi T, Jerling M (2008) Population pharmacokinetics of chloroquine and sulfadoxine and treatment response in children with malaria: suggestions for an improved dose regimen. Br J Clin Pharmacol 65(4):493-501. https://doi.org/10.1111/j.1365-2125. 2007.03050.x

24. Frisk-Holmberg M, Bergkvist Y, Domeij-Nyberg B, Hellstrom L, Jansson F (1979) Chloroquine serum concentration and side effects: evidence for dose-dependent kinetics. Clin Pharmacol Ther 25(3): 345-350. https://doi.org/10.1002/cpt1979253345

25. Frisk-Holmberg M, Bergqvist Y, Englund U (1983) Chloroquine intoxication Br J Clin Pharmacol 15(4):502-503. https://doi.org/10. 1111/j.1365-2125.1983.tb01540.x

26. Riou B, Barriot P, Rimailho A, Baud FJ (1988) Treatment of severe chloroquine poisoning. N Engl J Med 318(1):1-6. https://doi.org/ 10.1056/nejm198801073180101

27. Cui C, Zhang M, Yao X, Tu S, Hou Z, Jie En VS, Xiang X, Lin J, Cai T, Shen N, Song C, Qiao J, Zhang S, Li H, Liu D (2020) Dose selection of chloroquine phosphate for treatment of COVID-19 based on a physiologically based pharmacokinetic model. Acta Pharm Sin B 10(7):1216-1227. https://doi.org/10.1016/j.apsb. 2020.04.007

28. Liu J, Cao R, Xu M, Wang X, Zhang H, Hu H, Li Y, Hu Z, Zhong W, Wang M (2020) Hydroxychloroquine, a less toxic derivative of chloroquine, is effective in inhibiting SARS-CoV-2 infection in vitro. Cell Discov 6:16. https://doi.org/10.1038/s41421-0200156-0

29. Adelusi SA, Salako LA (1982) Kinetics of the distribution and elimination of chloroquine in the rat. Gen Pharmacol 13(5):433437. https://doi.org/10.1016/0306-3623(82)90110-0

30. Savarino A, Boelaert JR, Cassone A, Majori G, Cauda R (2003) Effects of chloroquine on viral infections: an old drug against today's diseases. Lancet Infect Dis 3(11):722-727. https://doi.org/10. 1016/s1473-3099(03)00806-5

Publisher's note Springer Nature remains neutral with regard to jurisdictional claims in published maps and institutional affiliations. 